\title{
Yerel yönetimlere uyarlanmış dengeli sonuç kartı uygulaması ve Küçükçekmece Belediyesi örneği
}

\author{
Application of balanced results card adapted to local goverments and \\ Küçükçekmece municipality example
}

\section{Nesrin Başpınar $^{1}$ (D) Turgay İkier \\ 1 Dr., Küçükçekmece Belediyesi, TÜRKIYE, e-mail: n.baspinar@kucukcekmece.bel.tr \\ 2 Küçükçekmece Belediyesi, TÜRKIYE, e-mail: t.ikier@kucukcekmece.bel.tr \\ 3 Dr., Adalar Belediyesi, TÜRKIYY, e-mail: naciyekaya88@gmail.com}

(1)

Naciye Kaya ${ }^{3}$

$\ddot{O} z$

İyi bir performans denetiminin, kamu hizmetlerinde hesap verebilirliği ve vatandaşın belediyeye olan güvenini arttırdığı bilinmektedir. Bu nedenle Dengeli Sonuç Kartı uygulaması, özellikle işletmelerde performansı ölçmede etkinliği ispatlanmış bir uygulama yöntemi olarak görülmektedir. Fakat yerel yönetimlerde bilinirliği çok azdır. Bu araştırmanın tüm yerel yerel yönetimlere ışık tutacak bir çalışma olacağı ve yerel yönetimlerde uygulanabilirliğinin artacağı düşünülmektedir.

Yapılan çalışma sonucunda; "Küçükçekmece Belediyesi Performans Karnesi" ortaya çıkartılmıştır. Dengeli Sonuç Kartında yer alan boyutlarm belediyelerin belirlemiş oldukları stratejik alanlara denk geldiği ve performans yönetimi konusunda belediyelerin Dengeli Sonuç Kartı uygulamasını yaptıklarını fakat uyguladıklarının farkında olmadıkları gözlemlenmiştir.

Anahtar kelimeler: stratejik yönetim, performans ölçümü, performans yönetimi, dengeli sonuç kartı

Jel kodlari: M1,L21,P47

\section{Abstract}

It is known that a good performance audit increases accountability in public services and the trust of citizens in the municipality. For this reason, the Balanced Scorecard application is seen as an application method with proven effectiveness in measuring performance, especially in enterprises. However, its awareness in local governments is very low.It is thought that this research will be a work that will shed light on all local local governments and its applicability in local governments will increase.

As a result of the study; Küçükçekmece Municipality Performance Report Card (Balance Scorecard) was prepared. In addition, it was observed that the dimensions in the Balanced Scorecard correspond to the strategic areas determined by the municipalities and that the municipalities have implemented the Balanced Scorecard for performance management, but they are not aware that they have implemented it.

Keywords: strategic management, performance measurament, performance management, balanced scorecard.

Jel codes: $M 1, L 21, P 47$

Citation/Atıf: BASPINAR, N., IKIER, T. \& KAYA, N., (2021). Yerel yönetimlere uyarlanmış dengeli sonuç kartı uygulaması ve Küçükçekmece Belediyesi örneği. Journal of Life Economics. 8(3):389-400, DOI: 10.15637/jlecon.8.3.10

Bu derginin içeriŏi Creative Commons Attribution-NonCommercial 4.0 Uluslararası Lisansı altında lisanslanmıştır.

Content of this journal is licensed under a Creative Commons Attribution-NonCommercial 4.0 International License. 


\section{GİRiş̧}

Ülkemizde “5018 sayılı Kamu Mali Yönetimi ve Kontrol Kanunu" ile kamu idarelerine Stratejik Plan ve Performans Programı hazırlama yükümlülüğü getirilmiştir. Stratejik Plan ve Performans Programları aracılığı ile kamuda performans ölçümü uygulamaları başlatılmıştır. Performans ölçümü kavramı en kısa ifade ile stratejilerin etkinliği ve faaliyetlerin verimliliği olarak ifade edilse de sadece performans göstergelerini kullanılarak örgütün genel performansını sağlamada yeterli olmamakta, kamu performansı için 'etki' kavramının diğer tüm unsurlarla bütünleşmesi gerekmektedir. Yerel yönetimler hizmet üreten kuruluşlar olduğu için karlılığın değil de etkinliğin ölçülmesi esastır. Bu nedenle performansı ölçmede kullanılan hedeflerin ölçülebilir olması esastır. Aynı zamanda güvenilir ve ulaşılabilir olması ve bütçeyle ilişkilendirmesi gerekmektedir. Yani sonuç göstergelerinin raporlanması aşamasında hedeflenen göstergelerle sonuçlarının kıyaslanması ve gerekli tedbirlerin alınması performans yönetiminde başarıyı ortaya koymaktadır. Stratejik Plan'da belirlenen hedeflerin yıllık ölçekte planlanması ya da yeni hedefler eklenmesi ile önceki süreçlerin devam etmesi sağlanır. Bu sayede birimler geçmiş performans programlarındaki hedefleri ve sonuçları görerek bir sonraki yıl için yeni süreçler belirleyerek takibini gerçekleştirirler. Kurumun amaç ve hedefleri, stratejik plandan çekilerek, her bir amaç ve hedefin performans hedefleri belirlenir. Bu performans hedefleri belirlenirken, birimler personel çalışma sürelerini girerek işçilik hesaplaması da yapabilmektedir. Faaliyetlere bağlı bütçeler girilerek sistem tarafından otomatik gider bütçesi hesaplaması yapılmaktadır.

\section{PERFORMANS YÖNETIMINDE SEKİZ BASİT ADIM UYGULAMASI}

Kurumsal performans yönetiminde 8 basit adım uygulamasının yapılmasına önemle dikkat edilmelidir. Bu adımlar sıralanacak olursa;

1. İş stratejisi geliştirmek ve tasfiye etmek: Stratejik olarak neyi ölçeceğimizi bilmek için misyon ve vizyonun belirlenmesi gerekmektedir. Her birimin stratejisi ve hedefi, kendi misyon ve başarı kriterine sahip olup aynı zamanda genel kapsamdaki şirket stratejisiyle aynı çizgide olmalıdır. Her bir birim için hesaplanabilir/sayılara dökülebilir hedeflerin içinde olduğu, net bir şirket stratejisi seçerek işe başlanmalı ve kendi hedefini, kurumun genel stratejisiyle bağdaştırabilmelidir. Kurumsal hedefe ör- nek olarak "geliri arttırma" verilebilir.

2. Başarı kriterlerini etkileyecek faktörleri belirlemek: Örneğin "geliri arttırma" için "satış yönetimi desteği" başarıyı etkileyecek bir faktör olabilir.

3. Stratejik yönetim hedeflerini belirlemek ve ölçmek: Kurumun amaçları ve vizyonunu gerçekleştirmek için atacağı adımlar stratejik hedefler olarak belirlenebilir. Aynı örnekten devam edersek, " yurtdışındaki satışları arttırmak" stratejik bir hedef olabilir.

4. Anahtar performans göstergelerini belirlemek: Kurumlar stratejilerinden sonra anahtar performans göstergelerini belirleyerek kurumun performansinin, stratejiye hizmet edip etmediğini tespit eder. Anahtar performans göstergeleri ürüne ya da projeye dair kuruma bir öngörü sağlayan ölçüm ya da ölçümler kombinasyonudur: "Bu kombinasyon üç başlıkta incelenebilir"; Başarı, Gelişim ve Analiz.

5. Bir ölçülebilir sistem yaratmak: Kurumlar ölçülebilir sistem yaratarak, ellerindeki verileri kullanmama riskini azaltmalıdır. Ölçüm, hedefe ulaşma yolundaki soruların cevabidir.

6. Süreçleri düzenli olarak geliştirmeye devam etmek: Sizi hedeften saptıran sürecin bölümlerini geliştirmeli ve sorunları çözmek için farklı metotlar kullanılmalı; Six Sigma ve Lean Sigma gibi. Anahtar performans göstergeleri, stratejik süreç planlama ile bulanabilecek hem diş hem iç etkenlerdir. Bunlar, stratejik planlama ve performans ölçüm sistemi arasında yer alan önemli bağlantılardır.

7. Kurumun aldığı riskleri öncelik sırasına koymak: Belirlediğimiz stratejik yönetimin risklerini ve hedefe ulaşamamanın riskini yönetebilmeliyiz. Hedefe ulaşamama olasılığını minimize etmek ve sistematik olarak uygun maliyetli seçimler yapmak için risk yönetimi uygulamalıyı.

8. Sonuç kartı temelli kararlar almak: Sonuç Kartı yöntemi, performans ölçümünü ileriye dönük olarak otomatik bir boyutta gerçekleştirme, yönetim kademelerini alt birimlere organik bağlayarak, kurumun misyon ve stratejisini yorumlama imkanı sağlar. Bu yöntem, etkili ve verimli yönetimin en önemli bileşenlerindendir. (Raynus, 2019) 
Tablo 1. Dengeli Sonuç Kartı Örneği

\begin{tabular}{|c|c|c|c|c|}
\hline \multicolumn{5}{|c|}{ DENGELİ SONUCC KARTI ÖRNEĞİ } \\
\hline Stratejik Amaçlar & Performans Ölçütleri & $\begin{array}{c}\text { Yapilması } \\
\text { Gerekenler }\end{array}$ & $\begin{array}{c}\text { Hedef } \\
\text { Performans }\end{array}$ & $\begin{array}{l}\text { Gerçekleşen } \\
\text { Performans }\end{array}$ \\
\hline \multicolumn{5}{|l|}{ Finasal Boyut } \\
\hline \multirow{3}{*}{ İşletmenin Değerini Arttırmak } & $\begin{array}{l}\text { Verimlilikten Kaynaklanan } \\
\text { kar artışı }\end{array}$ & $\begin{array}{l}\text { Maliyetleri ve } \\
\text { kullanılmayan } \\
\text { kapasiteyi yönetmek }\end{array}$ & $2.000 .000 \mathrm{USD}$ & 2.100 .000 USD \\
\hline & $\begin{array}{l}\text { Büyümekten Kaynaklanan } \\
\text { Kar Artış1 }\end{array}$ & $\begin{array}{l}\text { Müssteri ilişskilerini } \\
\text { güçlendirmek }\end{array}$ & 3.000 .000 USD & $3.420 .000 \mathrm{USD}$ \\
\hline & Gelir Artış & $\begin{array}{l}\text { Müșteri ilişskilerini } \\
\text { güçlendirmek }\end{array}$ & $6 \%$ & $6,48 \%$ \\
\hline \multicolumn{5}{|l|}{ Müşteri Boyutu } \\
\hline \multirow[b]{2}{*}{ Pazar Payını Büyütmek } & $\begin{array}{l}\text { Belirlenen bölümün Pazar } \\
\text { payını arttırmak }\end{array}$ & $\begin{array}{l}\text { Müsterilerin Muhtemel } \\
\text { gereksinimlerini } \\
\text { belirlemek }\end{array}$ & $6 \%$ & $7 \%$ \\
\hline & Yeni Müşteriler & $\begin{array}{l}\text { Yeni Müssteri Bölümleri } \\
\text { hedeflemek }\end{array}$ & 1 & 1 \\
\hline $\begin{array}{l}\text { Müş̧teri Memnuniyetini } \\
\text { arttırmak }\end{array}$ & $\begin{array}{l}\text { Müşteri Memnuniyeti } \\
\text { araştırması }\end{array}$ & $\begin{array}{l}\text { Satış birimlerinde } \\
\text { müstteri odakl1lığını } \\
\text { arttımak }\end{array}$ & $\begin{array}{c}\text { Müşterilerin } \\
\% 90 \text { 'nun en iyi iki } \\
\text { notu vermesi }\end{array}$ & $\begin{array}{l}\text { Müşterilerin } \\
\% 87^{\prime} \mathrm{i} \text { en iyi iki } \\
\text { notu vermiştir. }\end{array}$ \\
\hline \multicolumn{5}{|l|}{ Süreçler Boyutu } \\
\hline $\begin{array}{l}\text { Üretim kalitesini ve } \\
\text { verimliliği arttırmak }\end{array}$ & Verim & $\begin{array}{l}\text { Sorunların kaynağını } \\
\text { bulmak ve kaliteyi } \\
\text { arttımak }\end{array}$ & $78 \%$ & $79,50 \%$ \\
\hline $\begin{array}{l}\text { Müş̧teriye teslimat süresini } \\
\text { azaltmak }\end{array}$ & Sipariş teslimat süresi & $\begin{array}{l}\text { Sipariş teslimat sürelerini } \\
\text { düzenlemek }\end{array}$ & 30 gün & 30 gün \\
\hline $\begin{array}{l}\text { Belirlenmiş sipariş zamanına uyum } \\
\text { göstermek }\end{array}$ & Zamanında teslimat & $\begin{array}{l}\text { Sipariş teslimat } \\
\text { ișlemini düzenlemek }\end{array}$ & $92 \%$ & $90 \%$ \\
\hline Süreçleri Geliştirmek & $\begin{array}{l}\text { Üretim süreçlerinde } \\
\text { gerçekleşen önemli gelişme } \\
\text { sayısı }\end{array}$ & $\begin{array}{l}\text { Süreçleri değiştirmek } \\
\text { için ǔretimden ve } \\
\text { satıştan ar-ge birimleri } \\
\text { kurmak }\end{array}$ & 5 & 5 \\
\hline Üretim yetenekleri geliştirmek & $\begin{array}{l}\text { Gelişmiş Kontrol } \\
\text { Sistemlerinin olduğu } \\
\text { süreçlerin oranı }\end{array}$ & $\begin{array}{l}\text { Gelişmiş kontrol } \\
\text { sitemleri oluşturmak } \\
\text { için ar-ge birimleri } \\
\text { kurmak }\end{array}$ & $75 \%$ & $75 \%$ \\
\hline \multicolumn{5}{|l|}{ Öğrenme ve Gelişme Boyutu } \\
\hline $\begin{array}{l}\text { Çalışanlar ile kurumun } \\
\text { amaçlarımı aynı yöne } \\
\text { yöneltmek }\end{array}$ & $\begin{array}{l}\text { Çalış̧an memnuniyeti } \\
\text { araşırması }\end{array}$ & $\begin{array}{l}\text { Takım çalışmasını } \\
\text { teşvik etmek içiin } \\
\text { çalışanların katılımını } \\
\text { sağlamak }\end{array}$ & $\begin{array}{l}\text { Çalışanların } \\
\% 80 \text { 'nı en iyi iki } \\
\text { notu vermesi }\end{array}$ & $\begin{array}{l}\text { Çalışanların } \\
\% 88 \text { 'i en iyi iki } \\
\text { notu vermiştir }\end{array}$ \\
\hline Yetenekleri Geliştirmek & $\begin{array}{l}\text { Süreçlerde iyileştirilen } \\
\text { çalışan sayıs1 }\end{array}$ & $\begin{array}{l}\text { Çalıșan eğitim } \\
\text { programları yapmak }\end{array}$ & $90 \%$ & $92 \%$ \\
\hline Çalışanlara Yetki vermek & $\begin{array}{l}\text { Yönetim süreçlerinde yetki } \\
\text { verilen çalışan sayısı }\end{array}$ & $\begin{array}{l}\text { Yetkililerin karar verici } \\
\text { gibi değil de yönlendirici } \\
\text { gibi davranması }\end{array}$ & $85 \%$ & $90 \%$ \\
\hline $\begin{array}{l}\text { Bilgi işlem yeteneklerini } \\
\text { geliştirmek }\end{array}$ & $\begin{array}{l}\text { Zamanunda geri-besleme } \\
\text { alınan üretim süreçlerinin } \\
\text { sayısı }\end{array}$ & $\begin{array}{l}\text { Bilgi toplama işlevini } \\
\text { geliştirmek }\end{array}$ & $80 \%$ & $80 \%$ \\
\hline
\end{tabular}

Kaynak: Charles Horngen, Srikant Datar, George Foster, “Cost Accounting: A Managerial Emphasis”, Prentice Hall, 2003 , s.450.

\section{DENGELI SONUÇ KARTI UYGULAMASI İLE İLGİLI TANIMLAMALAR}

Üst yöneticiler, kurumun vizyonu ve stratejileri doğrultusunda, hedefler ve ölçüm kriterleri belirleyerek bir performans değerlendirme sistemi olan "Dengeli Sonuç Kartı" sistemini oluşturmaktadır. Yani performans verilerin in ne olacağı, hangi aralıklarla nasıl toplanacağının önceden belirlenerek, üst yöneticiye sunulduğu sisteme Dengeli Sonuç Kartı (Balanced Scorecard) denmektedir.

Performans yönetimi ile ilgili kar amaçlı kısa vadeli finansal ölçütlerin yetersiz olduğu ve performans ölçütlerinin belirlenirken finansal olmayan alanları da içermesi gerektiği belirtilmiştir (Johnson \& Kaplan, 1991). Kaplan ve Norton çalışmalarında; Dengeli Sonuç Kartı'nın (balance scorecard) finansal boyut, süreçler boyutu, müşteri boyutu ile öğrenme ve gelişme olmak üzere dört boyuttan oluştuğu ortaya koymuştur (Kaplan \& Norton, 1992). 1996 yılında ise Dengeli Sonuç Kartı'nın ilk örneğini oluşturmuştur (Kaplan \& Norton, 1996). Kaplan ve Norton tarafından yayinlanan The Balanced Scorecard kitabindan sonra Fortune'da yayınlanan 1000'e yakın kurumda uygulanmıştır (Niven, 2003, s. 23). 2003 yılında ise Charles ve Srikant tarafından Tablo 1'deki Dengeli Sonuç Kartı örneği Performans ölçütleri ile ortaya konulmuştur.

Yukarıdaki Tablo 1 (Horngen, Datar, \& Foster, 2003) 
örneğinde görüleceği üzere Stratejik hedeflere ulaşmak için belirlenmiş 12 stratejik amaç ve amaca ulaşıp ulaşmadığımızı ölçmek için 15 performans ölçütü ile her bir performans ölçütü için belirlenmiş bir hedef bulunmaktadır. Tablo 1'i aşağıda belirtilen açıklamalarla özetleyebiliriz:

\section{PERFORMANS YÖNETIMININ YASAL ALTYAPISI}

Türkiye'de performans yönetimini geliştirme çalışmaları 2003 tarihli ve 25326 sayılı resmî gazetede yayımlanarak yürürlüğe giren 5018 sayılı Kamu Mali Yönetimi ve Kontrol Kanunu çerçevesinde yürütülmektedir. Tüm kamu kurumlarında düzenlemeleri hedef alan performans yönetimi süreci için, Stratejik Planlama, Performans Esaslı Bütçeleme ile performans raporlama süreçlerini içeren düzenlemeler yapılmıştır. (Efe, 2012)

5018 sayılı Kamu Mali Yönetimi ve Kontrol Kanunu'nun "Stratejik planlama ve performans esaslı program bütçe" başlıklı Madde 9- "Kamu idareleri; kalkınma planları, Cumhurbaşkanı tarafından belirlenen politikalar, programlar, ilgili mevzuat ve benimsedikleri temel ilkeler çerçevesinde geleceğe ilişkin misyon ve vizyonlarını oluşturmak, stratejik amaçlar ve ölçülebilir hedefler saptamak, performanslarını önceden belirlenmiş olan göstergeler doğrultusunda ölçmek ve bu sürecin izleme ve değerlendirmesini yapmak amacıyla katılımcı yöntemlerle stratejik plan hazırlarlar.

Kamu idareleri, kamu hizmetlerinin istenilen düzeyde ve kalitede sunulabilmesi için bütçeleri ile program ve proje bazında kaynak tahsislerini; stratejik planlarına, yıllık amaç ve hedefleri ile performans göstergelerine dayandırmak zorundadırlar. Stratejik plan hazırlamakla yükümlü olacak kamu idarelerinin ve stratejik planlama sürecine ilişkin takvimin tespitine, stratejik planların politikalar, kalkınma planı ve programlarla ilişkilendirilmesine yönelik usul ve esaslar Cumhurbaşkanı tarafından belirlenir." Şeklinde düzenlenmiş olup, hüküm altına alınmıştır. (5018 sayılı Kanun)

\section{STRATEJIKK PLAN HAZIRLAMA ADIMLARI}

Stratejik Plan çalışmalarının başarıya ulaşabilmesi için Stratejik Plan dönemi sonunda ulaşılması istenilen amaç ve hedefler ile bunlara ulaşırken kullanılacak olan kaynakların birbiriyle örtüştürülmesi gerektiği gibi, ihtiyaç analizleri sonucunda ortaya çıkan alanlara daha fazla öncelik verilmelidir.

Belediyeler yerel seçimler yapıldıktan sonra gelecek beş yıllarını planladıkları stratejik planlarını hazırlarlar. Stratejik planlar hazırlanırken belli adımların yerine getirilmesi gerekmektedir.

- Bunların başında kurumun mevcut durum anali- zi yapması gelmektedir. Kurum fiziki, ekonomik ve insan kaynakları altyapısını gözden geçirmeli, faaliyet alanları ve ürün hizmetleri ile ilgili çalışmalar yapmalıdır. Bunun yanında paydaş analizleri ve GZFT (Güçlü-Zayıf, Fırsat-Tehdit) analizleri yaparak katılımcılığı sağlayabilmelidir.

- Bundan sonraki aşamada ise beş yılın sonunda ulaşmayı hedeflediği vizyonu ve o vizyona ulaşmasını sağlayacak misyon, stratejik amaç ve stratejik hedefler ile stratejilerini belirlemelidir.

- $\quad$ Stratejik plandan sonra yıllık performans programları hazırlanmalı, yıllık performans programları ile stratejik plan ve bütçe arasındaki bağ oluşturulmalıdır. Performans programları gelecek bir yıl içinde hedeflere ulaşmak için yıllık performans hedeflerinin belirlendiği ve bu hedefleri gerçekleştirmek için faaliyet, projelerin ve performans hedeflerini ölçek için performans göstergelinin kullanıldığı programlardır. Performans programları hazırlanırken hükümet planları ve programlar da dikkate alınmalıdır. Performans döneminin başladığı 01 Ocak itibarı ile üst yönetime üçer aylık performans izleme ve değerlendirme raporları sunulmaktadır. Bu raporlar ilgili harcama birimlerinin gerçekleştirmiş oldukları performans gösterge gerçekleşmeleri dikkate alınarak hazırlanmaktadır. Üst yönetici harcama birimlerinin performansını izleme raporunda görmekte ve başarısız gözüken ve yılsonunda ulaşılamayacak hedefler için önceden tedbir alabilmektedir.

- Bir yılın sonunda performans programında planlanan hedeflerin ne kadarına ulaşıldığını ölçmek ve daha sonra da değerlendirmeleri yapmak üzere ilgili yıl için faaliyet raporu hazırlanmaktadır.

- Faaliyet raporları üst yöneticilerin hesap vermelerini sağlayan şeffaflık gereği hazırlanmış olan raporlardır. Birim içinde kurumun harcamış olduğu mali kaynaklar ve insan kaynağı ile fiziki kaynakların tamamı faaliyet raporlarında gösterilmektedir. Faaliyet raporlarında harcama birimlerinin yapmış olduğu tüm faaliyetlerin detayları ve açılamaları ile performans değerlendirmeleri yer almaktadır.

\section{PERFORMANS ÖLÇÜMÜ VE PERFORMANS DEĞERLENDİRMESI}

Belediyeler açısından performans yönetimi kavramı; kurumun, bireyler ve gruplar üzerinde hem fikir olunan stratejilerin, amaç ve hedeflerinin planlamasıdır. Sistemsel olarak bu amaç ve hedeflere ulaşılıp ulaşılmadığının performans hedefleri ve bu hedeflere ulaşmak için göstergeler aracılığıyla ölçülmesi, çıktı ve sonuçların değerlendirilmesi gerekir. Geri bildirim yapılarak performansın geliştirilmesi için gerekli önlemlerin alınması gerekir. Sonuç olarak performans 
yönetimi uygulanması, yüksek performansın ödüllendirilmesi süreçlerini de içine alan bütüncül bir yönetim anlayışı olarak tanımlanabilir (Yılmaz, 2019).

Performans yönetiminin etkili olabilmesi için kurum kaynaklarının tamamını (insan kaynağ kaynaklar) kapsaması gerekmektedir. Yine kurumun, performans ölçümünden istedikleri faydayı sağlayabilmeleri için; kurumun hedefleri ile uyumlu ve elde edilen performans çıktı sonuçlarının da güvenilir olması gerekmektedir.

Performans Yönetiminin birer parçası olan performans ölçümü ve performans değerlendirmesi birbirini tamamlamakla birlikte iki ayrı araçtır. Performans ölçümü, kamu hizmetlerinin sunulmasında ve faaliyetlerin yürütülmesinde kullanılan girdi, çıktı, kalite, verimlilik ve sonuçlarla ilgili göstergelere ilişkin bilgiler vermekte, amaç ve hedeflere ulaşılıp ulaşılmadığına odaklanmaktadır. Performans değerlendirmesi ise, mevcut durumu belirleme, amaç ve hedefleri saptama, misyon oluşturma, performans göstergelerini oluşturma, ölçme ve değerlendirmedir. Diğer bir ifade ile amaç ve hedeflere ilişkin bilgilerin ayrıntılı bir şekilde incelenmesi, bulguların yorumlanması, başarı veya başarısızlığın arkasındaki nedenlerin araştırılması, alternatiflere ilişkin tavsiye ve görüşleri kapsamaktadır.

Performans değerlendirmesinin temel amac1, kamu kaynaklarının ekonomik, verimli ve etkili bir şekilde elde edilmesi ve kullanılmasında etkinliğin arttırılmasını sağlamaktır. Performans ölçümü ve performans değerlendirmesinin ortak amacı ise hizmet sunumu ve programların etkililiğinin artırılmasına yönelik kaynak tahsisi sağlamaktır. Öte yandan performans ölçümü, yönetime karşı uyarıcı bir sistem olup, kamuoyuna karşı da hesap verebilirliği artırıcı bir araç olarak hizmet etmektedir.

Performans ölçümü, kamusal hizmetlerin kalitesinin arttırılmasında büyük role sahiptir. Kamusal hizmetlerin sunumunda etkin rol oynayan personelin bireysel performansının ölçülmesi, performans ölçümü sayesinde yapılabilmektedir. Personelin bireysel performans ölçümlerinin başarı ya da başarısızlığının altında farklı etmenler yatmaktadır. Bunlar; eğer personel kendi uzmanlık alanı ile ilgili bir yerde çalıştırılmıyorsa ya da çalıştığı alanda yeterince eğitim almamışsa, performansının düşük çıkma nedenleri olarak görülebilir. Kamusal hizmetlerde çalışan personellerin, çalışmış olduğu alan ve sorumlu olduğu mevzuat konusunda gerekli eğitimleri almış olmaları, bireysel performanslarının yüksek çıkmasına yol açabilir Bu da kamusal hizmetlerin kalitesine etki ederek kamusal hizmet alanların memnuniyet düzeyinin yüksek olmasına katkı sağlar.
Belediyeler de diğer tüm kamu kuruluşları gibi performans ölçümü yapma konusunda sorumludurlar. Bu sorumluluk ilgili mevzuatlarda belirtilmiştir.

\section{KÜÇÜKÇEKMECE BELEDİYESİ 2017 YILI PERFORMANS SONUÇLARININ ÖLÇÜLMESİ}

Performans sonuçlarının ölçülmesi için; bir yılın sonunda ulaşılması planlanan performans hedefleri, faaliyet ve projeler ile bütçeleri, hedeflerin ne oranda gerçekleştiğini ölçmek için kullanılan performans göstergeleri kullanılmaktadır. "Küçükçekmece Belediyesi Performans Ölçümü" için web tabanlı otomasyon sistemi Strateji Geliştirme Müdürlüğü tarafından geliştirilmiş ve kullanılmaya başlanmıştır. Web tabanlı Strateji Geliştirme Bilgi Sistemi üzerinde performans ölçümü en etkili şekilde tasarlanmış ve ilgili mevzuatlar dikkate alınarak hukuki bir boşluğun kalmasının önüne geçilmiştir. (https://kucukcekmece.istanbul)

Strateji Geliştirme Bilgi Sistemi üzerinden performans ölçümü şu şekilde yapılmaktadır;

1. Harcama birimlerinin beş yıl boyunca sorumlu olacağ1 stratejik alanlar, stratejik amaçlar ve stratejik hedefler Strateji Geliştirme Bilgi Sistemi'nden otomatik olarak çekilmektedir. Gelecek bir yıl için hazırlanacak olan performans programında yer alacak olan performans hedefleri stratejik amaç ve stratejik hedeflerle ilişkilendirilmektedir.

2. Performans hedeflerini gerçekleştirmek için faaliyet ve projeler belirlenmekte ve bu faaliyet ve projeleri yerine getirmek için kaynak tahsisi yapılmaktadır. Faaliyet ve projeleri hangi düzeyde gerçekleştirdiğimizi ölçmek için performans göstergeleri belirlenmektedir.

Küçükçekmece Belediyesinin Stratejik Alan ve Stratejik Amaçlarının gösterildiği tablo aşağıda gösterilmiştir (Tablo 2) 
Tablo 2. 2015-2019 Yilları Stratejik Alan ve Stratejik Amaçlara İlişkin Tablo

\begin{tabular}{|c|c|}
\hline \multicolumn{2}{|c|}{ "KÜCÜKÇEKMECE BELEDIYESI STRATEJIK ALAN VE STRATEJIK AMAÇLARI" } \\
\hline Stratejik Alan 1 & İmar Ve Șehircilik \\
\hline Stratejik Amaç 1 & $\begin{array}{l}\text { İlçenin modern, sosyal, ekonomik ve fiziksel gelişimine yön vererek } \\
\text { yaşam kalitesi yüksek, güvenli, estetik sürdürülebilir bir ilçe } \\
\text { mimarisinin oluşumuna katkı sağlamak }\end{array}$ \\
\hline Stratejik Alan 2 & Cevre Ve Temizlik Hizmetleri \\
\hline Stratejik Amaç 2 & $\begin{array}{l}\text { Sağllklı yașam alanları olan, ekolojik dengenin korunduğu, yüksek } \\
\text { çevre standartlarına sahip, sürdürülebilir ve özgün bir çevre } \\
\text { oluşturmak }\end{array}$ \\
\hline Stratejik Amaç 3 & $\begin{array}{l}\text { Ekolojik dengeyi bozacak kirlilikleri etkin ve çağdaş yöntemlerle } \\
\text { ortadan kaldırarak yaşanabilir, temiz bir ilçe oluştưmak }\end{array}$ \\
\hline Stratejik Alan 3 & Kültür Hizmetleri \\
\hline Stratejik Amaç 4 & $\begin{array}{l}\text { İlçenin kültür, spor, eğitim, sanat ve sosyal alanlarının } \\
\text { zenginleştirilmesine katkı sunarak yaşam kalitesini yükseltmek }\end{array}$ \\
\hline Stratejik Alan 4 & Sosyal Belediyecilik \\
\hline Stratejik Amaç 5 & $\begin{array}{l}\text { Birlik ve dayanıssma ruhuyla, sosyal hizmetleri çok yönlü ve etkin hale } \\
\text { getirerek vatandaşların sosyal yaşamının desteklenmesine katkı } \\
\text { sunımak }\end{array}$ \\
\hline Stratejik Alan 5 & Illçe ve Toplum Düzeni \\
\hline Stratejik Amaç 6 & $\begin{array}{l}\text { Düzenli, sağllkli, huzur ve esenlik dolu, hijyeni esas alan, yaşanılabilir } \\
\text { bir ilçe için etkin ve verimli denetim sunmak }\end{array}$ \\
\hline Stratejik Alan 7 & Afet Yönetimi \\
\hline Stratejik Amaç 7 & $\begin{array}{l}\text { Afet bilinci ve yönetimini geliştirerek, afetle mücadele kapasitesini } \\
\text { artırmak }\end{array}$ \\
\hline Stratejik Alan8 & Sağlık Hizmetleri \\
\hline Stratejik Amaç 8 & $\begin{array}{l}\text { İlçede yaşayan her bir canlının sağlık standartlarının yükseltilmesine } \\
\text { katkı sunmak }\end{array}$ \\
\hline Stratejik Alan 9 & Kurumsal Gelişim Ve Kapasite Yönetimi \\
\hline Stratejik Amaç 9 & $\begin{array}{l}\text { "Önce insan" anlayıșı ile verimli, kaliteli ve etkin personel politikası } \\
\text { geliştirerek sunulan hizmet kalitesini yükseltmek }\end{array}$ \\
\hline Stratejik Amaç 10 & $\begin{array}{l}\text { Yenilikçi ve araștırmacı yöntemlerle mali kaynaklarımızı ve } \\
\text { varliklarımızı etkin, verimli ve hesap verebilir bir anlayışla yönetmek }\end{array}$ \\
\hline Stratejik Amaç 11 & $\begin{array}{l}\text { Modern çağın gereklerine uyum sağlayarak kurumun ve ilgili } \\
\text { paydaşların bilgi, iletişim ve lojistik hizmetlerden en verimli şekilde } \\
\text { yararlanmasını sağlamak }\end{array}$ \\
\hline Stratejik Amaç 12 & $\begin{array}{l}\text { "Etkin denetim mekanizmalar1 yoluyla kurumsal karar ve süreçlerin } \\
\text { hukukun temel ilkeleri çerçevesinde yürütülmesini sağlamak } \\
\text { (mevzuat)" }\end{array}$ \\
\hline Stratejik Amaç 13 & $\begin{array}{l}\text { Vatandaş memnnuniyetini esas alan, güler yüzlü, modern bir anlayışla, } \\
\text { paydaşlarla işbirliği içerisinde kurumun ve ilçenin görünürlük ve } \\
\text { bilinirligigini artırmak }\end{array}$ \\
\hline
\end{tabular}

Tablo 3. Kavramsal Karşılaştırma Tablosu

\begin{tabular}{|c|c|c|c|c|c|c|}
\hline \multicolumn{7}{|c|}{$\begin{array}{c}\text { Kaplan ve Norton'un önerdiği Dengeli Sonuç Kartı uygulamasındaki kavramlar ile } \\
\text { "Küçükçekmece Belediyesi’nde Kullanılan Dengeli Sonuç Kartı" Uygulamasının } \\
\text { Kavramsal Karşılaştırması }\end{array}$} \\
\hline Boyutlar & Amaçlar & Ölçütler & $\begin{array}{l}\text { Yapılması } \\
\text { Gerekenler }\end{array}$ & $\begin{array}{c}\text { Hedef } \\
\text { Performans }\end{array}$ & $\begin{array}{l}\text { Gerçekleşen } \\
\text { Performans }\end{array}$ & $\begin{array}{l}\text { Dengeli Sonuç } \\
\text { Kartı (Balance } \\
\text { Scorecard) }\end{array}$ \\
\hline $\begin{array}{c}\text { Stratejik } \\
\text { Alanlar }\end{array}$ & $\begin{array}{l}\text { Stratejik } \\
\text { Amaçlar }\end{array}$ & $\begin{array}{c}\text { Performans } \\
\text { Hedefi }\end{array}$ & $\begin{array}{l}\text { Performans } \\
\text { Göstergeleri }\end{array}$ & $\begin{array}{l}\text { Performans } \\
\text { Gösterge } \\
\text { Hedefi }\end{array}$ & $\begin{array}{l}\text { Performans } \\
\text { Gösterge } \\
\text { Gerçekleşmesi }\end{array}$ & $\begin{array}{c}\text { "Küçükçekmece } \\
\text { Belediyesi } \\
\text { Dengeli Sonuç } \\
\text { Kartı" }\end{array}$ \\
\hline
\end{tabular}

Not: Tablo'3 de Dengeli Sonuç Kartı uygulamasına göre ve Küçükçekmece Belediyesi'nin performans yönetimi alanında kullanmış oldukları kavramların karşılaştırması gösterilmiştir. 
Tablo 4. "Küçükçekmece Belediyesi Dengeli Sonuç Kartı Örneği"

\begin{tabular}{|c|c|c|c|c|c|}
\hline \multicolumn{6}{|c|}{ DENGELI SONUÇ KARTI ÖRNEĞİ } \\
\hline Boyutlar & Amaçlar & Ölçütler & Yapılmasi Gerekenler & $\begin{array}{c}\text { Hedef } \\
\text { Performans }\end{array}$ & $\begin{array}{l}\text { Gerçekleşen } \\
\text { Performans }\end{array}$ \\
\hline $\begin{array}{l}\text { Stratejik } \\
\text { Alanlar }\end{array}$ & Stratejik Amaçlar & Performans Hedefi & Performans Göstergeleri & $\begin{array}{c}\text { Performans } \\
\text { Gösterge Hedefi }\end{array}$ & $\begin{array}{l}\text { Performans Gösterge } \\
\text { Gerçekleşmesi }\end{array}$ \\
\hline \multirow{3}{*}{$\begin{array}{l}\text { İmar ve } \\
\text { Şehircilik }\end{array}$} & \multirow{3}{*}{$\begin{array}{l}\text { İlçenin modern, sosyal, } \\
\text { ekonomnik ve fiziksel } \\
\text { gelişimine yön vererek } \\
\text { yaşam kalitesi yüksek, } \\
\text { güverlili, estetik sürdürülebilir } \\
\text { bir iļ̧e mimarisinin } \\
\text { oluşummuna katk sağlamak }\end{array}$} & \begin{tabular}{|l} 
Yaămur suyu şebekesini \\
geliş̧tirerek ilçedeki su \\
taşkmlannu önlemek
\end{tabular} & $\begin{array}{l}\text { Yapımı gerçeklessen yağmur } \\
\text { suyu kanal uzunluău }\end{array}$ & 2000 & 3850 \\
\hline & & $\begin{array}{l}\text { İlçemizdeki mevcut yolları } \\
\text { iyilesstirerek erişebilirliği ve } \\
\text { ulaşım konfornu artırnak }\end{array}$ & $\begin{array}{l}\text { Yol bakum onarmm } \\
\text { eksiklliklerinin tamarnlartma } \\
\text { orau }\end{array}$ & 100 & 90,99 \\
\hline & & $\begin{array}{l}\text { Trafik işaretlerini } \\
\text { düzenleyerek trafik akışııı } \\
\text { rahatlatmak }\end{array}$ & Takılan tabela sayısı & 750 & 900 \\
\hline Boyutlar & Amaçlar & Ölçütler & Yapilmasi Gerekenler & $\begin{array}{c}\text { Hedef } \\
\text { Performans }\end{array}$ & $\begin{array}{l}\text { Gerceldesen } \\
\text { Performans }\end{array}$ \\
\hline $\begin{array}{l}\text { Stratejik } \\
\text { Alanlar }\end{array}$ & Stratej ik Amaçlar & Performans Hedefi & Performans Göstergeleri & $\begin{array}{c}\text { Performans } \\
\text { Gösterge Hedefi }\end{array}$ & $\begin{array}{c}\begin{array}{c}\text { Performans Gösterge } \\
\text { Gerçekleşmesi }\end{array} \\
\end{array}$ \\
\hline \multirow{3}{*}{$\begin{array}{c}\text { Çevre ve } \\
\text { Temizlik } \\
\text { Hizmetleri }\end{array}$} & \multirow{3}{*}{ 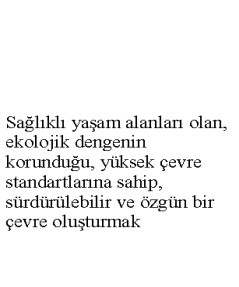 } & $\begin{array}{l}\text { Otomasyon sistemi ve LED } \\
\text { aydinlatma sistemiyle } \\
\text { tasarruf sağlamak }\end{array}$ & $\begin{array}{l}\text { Otomasyon sistemi kurulan } \\
\text { park say1sı }\end{array}$ & 1 & 2 \\
\hline & & $\begin{array}{l}\text { Kişi başna düşen yeşil alan } \\
\text { miktarnn artırmak ve } \\
\text { sürekliligigini sağlamak }\end{array}$ & Dikilen ağaç âdeti & 7000 & 9132 \\
\hline & & $\begin{array}{l}\text { Temizlik faaliyetlerinde } \\
\text { sürdürülebilitiliği sağlamak }\end{array}$ & Vatandaş memnuniyet oranı & 77 & 77 \\
\hline \multirow{3}{*}{$\begin{array}{c}\text { Kültür } \\
\text { Hizmetleri }\end{array}$} & \multirow{3}{*}{$\begin{array}{l}\text { Ilçemizin, kültür, spor, } \\
\text { eğitim, sanat ve sosyal } \\
\text { alanlarnunn } \\
\text { zenginleştirilmesine katk1 } \\
\text { sunarak insarumuznu hayat } \\
\text { standardın yükseltmek. }\end{array}$} & $\begin{array}{l}\text { Çocuk, genç ve yetisksinlerin } \\
\text { sürekli gelişimlerini esas } \\
\text { alarakt tümilçe halkunt eğitim } \\
\text { etkinlikleriyle buluşurmak }\end{array}$ & $\begin{array}{l}\text { Yapilan seminer ve } \\
\text { konferans sayisı }\end{array}$ & 119 & 119 \\
\hline & & $\begin{array}{l}\text { Vatandaşlarnn kisisisel } \\
\text { gelişimlerini temel hayat } \\
\text { beecri eğitimleri ile } \\
\text { destekleyerek geliştirmek. }\end{array}$ & $\begin{array}{l}\text { Bilgi evlerinde kurulan } \\
\text { temel hayat becerileri } \\
\text { atölyesi sayisı }\end{array}$ & 10 & 13 \\
\hline & & $\begin{array}{l}\text { İlçe hallının kültürr-sanat } \\
\text { etkinliklerine katilınuru } \\
\text { artırmak }\end{array}$ & $\begin{array}{l}\text { İlçe halkının külttirr-sanat } \\
\text { etkinliklerine katılım oranı }\end{array}$ & 32 & 43 \\
\hline
\end{tabular}

Not: Tablo 4'de Küçükçekmece Belediyesi'nin sunmuş olduğu hizmet alanları ve bu alanlarda performans yönetimi konusunda yaptığı çalışmalarla ilgili örnekler yer almaktadır.

Performans programı hazırlanırken ağırlıklı olarak çıktı, sonuç, verimlilik, kalite göstergeleri kullanılmaktadır. Bundaki amaç bütçenin ağırlıklı olarak kullanıldığı işler ile kurumsal kaliteyi arttıracak işlere yoğunlaşmaktır. 


\section{KÜÇÜKÇEKMECE BELEDİYESİ 2017 YILI PERFORMANS SONUÇLARININ DEĞERLENDİIILMESI}

2017 yılı itibari ile Küçükçekmece Belediyesince gerçekleştirilmesi hedeflenen 419 göstergenin 342 tanesi yani \%81'inin gerçekleşmesi; hedeflerinin $\% 85$ ve üstü olarak sonuçlanmıştır. Kurumsal göstergelerden 25 tanesi iyi, 29 gösterge orta, 5 tanesi zayıf, 18 tanesi ise çok zayıf olarak sonuçlanmıştır (Tablo 5).

İstanbul İli Küçükçekmece Belediyesi'nin “Stratejik Plan" da yer alan Stratejik Amaçlarının 2017 yılı itibari ile yıllık hedeflerinin gerçekleşme oranları değerlendirildiğinde (Tablo 6);

- “İlçenin çağdaş, sosyo ekonomik ve fiziksel gelişimine yön vererek, yaşam kalitesi yüksek, güvenli, estetik sürdürülebilir bir ilçe mimarisinin oluşumuna katkı sağlamak" Stratejik amacın gerçekleştirilmesi ile ilgili olarak; 2017 yılında toplam 46 gösterge ile faaliyetler gözlemlenmiştir. Bu göstergelerin \%72'si yani 33 tanesi çok iyi olup, hedeflenen değerlere ulaşılmıştır. Diğer 4 amaç iyi, 4 amaç orta ve 5 amaç çok zayıf olarak gerçekleşmiştir. Sonuç itibariyle bu amacı gerçekleştirmek için göstergelerin 41 tanesi yani \%90'1 orta ve ortanın üstünde değerlere ulaşmış olup, 5 gösterge yani \%10’lı bir bölümü gerçekleşme hedefine ulaşmada zayıf kalmıştır.

- “Sağlıklı yaşam alanları olan, ekolojik dengenin korunduğu, yüksek çevre standartlarına sahip, sürdürülebilir ve özgün bir çevre oluşturmak" Stratejik amacın gerçekleştirilmesi ile ilgili olarak; 2017
Tablo 5. Performans Göstergeleri Başarı Düzeyi Değerlendirme Sistemi

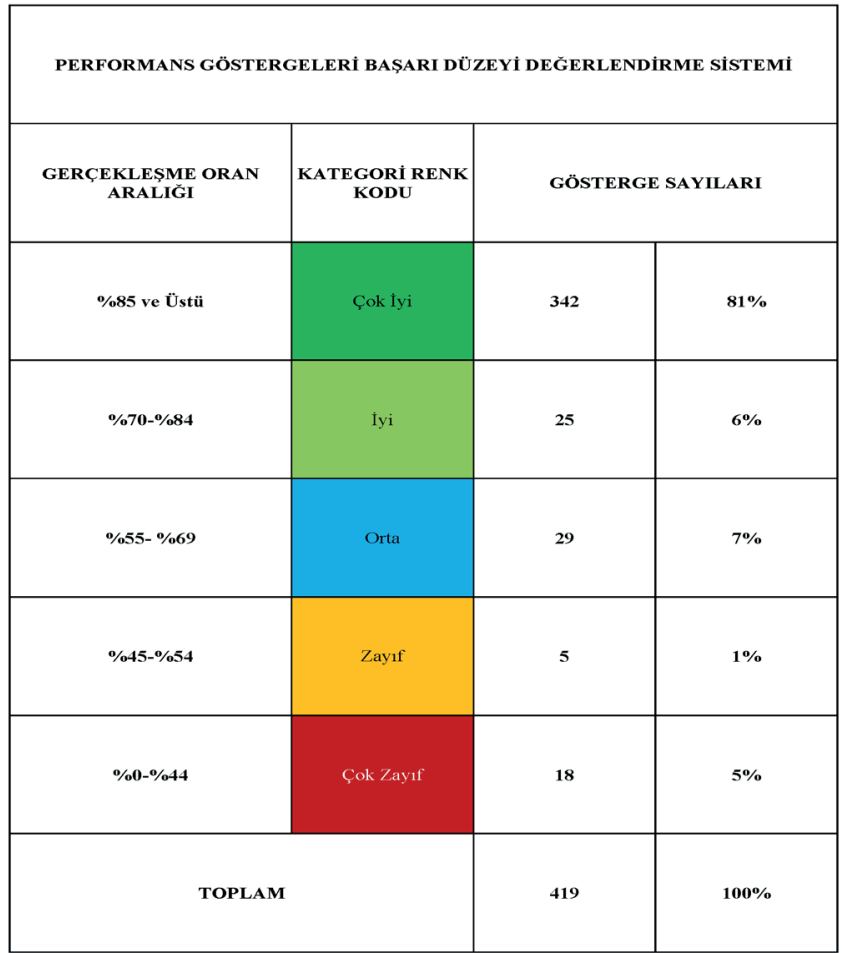

yılında toplam 18 gösterge ile faaliyetler gözlemlenmiştir. Bu göstergelerin \%72'si yani 13 tanesi çok iyi olup, hedeflenen değerlere ulaşılmıştır. Diğer 1 amaç iyi, 1 amaç orta ve 3 amaç çok zayıf olarak gerçekleşmiştir. Sonuç itibariyle bu amacı gerçekleştirmek için göstergelerin 15 tanesi yani \%84'ü orta ve ortanın üstünde değerlere ulaşmış olup, 3 gösterge yani \%16'lık bir bölümü gerçekleşme hedefine ulaşmada zayıf kalmıştır.

Tablo 6. Stratejik Amaçlara Göre Göstergelerin Başarı Düzeyi Değerlendirme Tablosu

\begin{tabular}{|c|c|c|c|c|c|c|c|c|c|c|c|c|c|c|c|c|c|c|c|c|c|c|c|c|c|c|}
\hline \multicolumn{27}{|c|}{ STRATEJIK AMACLARA GÖRE GÖST ERGELERIN BASARI DÜZEYİ DEĞERLENDİRME TABLOSU } \\
\hline \multirow{2}{*}{\begin{tabular}{|l} 
Kategor \\
i Renk \\
Kodu
\end{tabular}} & \multicolumn{2}{|c|}{ SA1 } & \multicolumn{2}{|c|}{ SA2 } & \multicolumn{2}{|c|}{ SA3 } & \multicolumn{2}{|c|}{ SA4 } & \multicolumn{2}{|c|}{ SA5 } & \multicolumn{2}{|c|}{ SA6 } & \multicolumn{2}{|c|}{ SA7 } & \multicolumn{2}{|c|}{ SA8 } & \multicolumn{2}{|c|}{ SA9 } & \multicolumn{2}{|c|}{ SA10 } & \multicolumn{2}{|r|}{ SA11 } & \multicolumn{2}{|c|}{ SA12 } & \multicolumn{2}{|c|}{ SA13 } \\
\hline & Ade & $\%$ & Ade & $\%$ & Ade & $\%$ & Ade & $\%$ & Ade & $\%$ & $\underset{t}{\text { Ade }}$ & $\%$ & Ade & $\%$ & Ade & $\%$ & Ade & $\%$ & Ade & $\%$ & Ade & $\%$ & Ade & $\%$ & Ade & $\%$ \\
\hline Cok lyi & 33 & 72 & 13 & 72 & 8 & 72,73 & 42 & 91 & 28 & 80 & 15 & 78,95 & 15 & 100 & 12 & 70,59 & 6 & 100 & 29 & 85,29 & 63 & 85,14 & 7 & 87,5 & 71 & 78,89 \\
\hline $\mathbf{i} \mathbf{y} \mathbf{i}$ & 4 & 9 & 1 & 6 & 0 & 0 & 3 & 7 & 3 & 8,57 & 2 & 10,53 & 0 & 0 & 1 & 5,88 & 0 & 0 & 1 & 2,94 & 4 & 5,41 & 0 & 0 & 6 & 6,67 \\
\hline Orta & 4 & 9 & 1 & 6 & 3 & 27,27 & 1 & 2 & 3 & 8,57 & 2 & 10,53 & 0 & 0 & 2 & 11,76 & 0 & 0 & 1 & 2,94 & 6 & 8,11 & 1 & 12,5 & 5 & 5,56 \\
\hline Zayif & 0 & 0 & 0 & 0 & 0 & 0 & 0 & 0 & 1 & 2,86 & 0 & 0 & 0 & 0 & 0 & 0 & 0 & 0 & 0 & 0 & 1 & 1,35 & o & o & 3 & 3,33 \\
\hline $\begin{array}{l}\text { Cok } \\
\text { Zayif }\end{array}$ & 5 & 10 & 3 & 16 & 0 & 0 & 0 & 0 & 0 & 0 & 0 & 0 & 0 & 0 & 2 & 11,76 & 0 & 0 & 3 & 8,82 & o & o & 0 & 0 & 5 & 5,56 \\
\hline Toplam & 46 & $\begin{array}{l}100 \\
\%\end{array}$ & 18 & $\begin{array}{l}100 \\
\%\end{array}$ & 11 & $\begin{array}{l}100 \\
\%\end{array}$ & 46 & $\begin{array}{l}100 \\
\%\end{array}$ & 35 & $\begin{array}{l}100 \\
\%\end{array}$ & 19 & $\begin{array}{l}100 \\
\%\end{array}$ & 15 & $\begin{array}{l}100 \\
\%\end{array}$ & 17 & $\begin{array}{l}100 \\
\%\end{array}$ & 6 & $\begin{array}{l}100 \\
\%\end{array}$ & 34 & $\begin{array}{l}100 \\
\%\end{array}$ & 74 & $\begin{array}{l}100 \\
\%\end{array}$ & 8 & $\begin{array}{l}100 \\
\%\end{array}$ & 90 & $\begin{array}{l}100 \\
\%\end{array}$ \\
\hline
\end{tabular}


- “Ekolojik dengeyi bozacak kirlilikleri etkin ve çağdaş yöntemlerle ortadan kaldırarak yaşanabilir, temiz bir ilçe oluşturmak" Stratejik amacın gerçekleştirilmesi ile ilgili olarak; 2017 yılında toplam 11 gösterge ile faaliyetler gözlemlenmiştir. Bu göstergelerin $\% 72,73$ yani 8 tanesi çok iyi olup, hedeflenen değerlere ulaşılmıştır. Diğer 3 amaç orta seviyede gerçekleşmiştir. İlgili amacı gerçekleştirmek için göstergelerin 11 tanesi yani $\% 100$ 'ü orta ve ortanın üstünde bir değere sahip olarak gerçekleşmiştir.

- “İlçenin kültür, spor, eğitim, sanat ve sosyal alanlarının zenginleştirilmesine katkı sunarak yaşam kalitesini yükseltmek" Stratejik amacın gerçekleştirilmesi ile ilgili olarak; 2017 yılında toplam 46 gösterge ile faaliyetler gözlemlenmiştir. Bu göstergelerin \%91'i yani 42 tanesi çok iyi olup, hedeflenen değerlere ulaşılmıştır. Diğer 3 amaç iyi, 1 amaç orta olarak gerçekleşmiştir. Sonuç itibariyle bu amacı gerçekleştirmek için göstergelerin 46 tanesi yani \%100'ü orta ve ortanın üstünde bir değere sahip olarak gerçekleşmiştir.

- “Birlik, beraberlik ve dayanışma içinde, sosyal faaliyetleri çok yönlü ve etkin hale getirerek vatandaşların sosyal yaşamının desteklenmesine katkı sunmak" Stratejik amacın gerçekleştirilmesi ile ilgili olarak; 2017 yılında 35 gösterge ile faaliyetler gözlemlenmiştir. Bu göstergelerin \%80'i yani 28 tanesi çok iyi olup, hedeflenen değerlere ulaşılmiştır. Diğer 3 amaç iyi, 3 amaç orta, 1 amaç zayıf olarak gerçekleşmiştir. Sonuç olarak bu amacı gerçekleştirmek için göstergelerin 34 tanesi yani $\% 97,14$ 'si orta ve ortanın üstünde bir değere sahip olup 1 gösterge yani \%2,86'lik bir bölümü gerçekleşme değerine ulaşmada zayıf kalmıştır.

- “Düzenli, sağlıklı, huzur ve esenlik dolu, hijyeni esas alan, yaşanılabilir bir ilçe için etkin ve verimli denetim sunmak" Stratejik amacın gerçekleştirilmesi ile ilgili olarak; 2017 y1lında toplam 19 gösterge ile faaliyetler gözlemlenmiştir. Bu göstergelerin \%78,95'i yani 15 tanesi çok iyi olup, hedeflenen değerlere ulaşılmıştır. Diğer 2 amaç iyi, 2 amaç orta olarak gerçekleşmiştir. Sonuç olarak bu amacı gerçekleştirmek için göstergelerin 19 tanesi yani \%100'ü orta ve ortanın üstünde bir değere sahip olup olarak gerçekleşmiştir.

- "Afet bilinci ve yönetimini geliştirerek, afetle mücadele kapasitesini artırmak" Stratejik amacin gerçekleştirilmesi; 2017 yılında 15 gösterge ile faaliyetler izlenmiştir. Göstergelerden \%100'ü, 15 tanesi için çok iyi bir şekilde hedeflenen değerlere ulaşılmıştır. Nihai olarak bu amacı gerçekleştirmek için göstergelerin 15 tanesi yani \%100'ü orta ve ortanın üstünde bir değere sahip olarak gerçekleşmiştir.
- "İlçede yaşayan bütün canlıların sağlık standartlarının yükseltilmesine katkıda bulunmak" Stratejik amacın gerçekleştirilmesi; 2017 yılında toplam 17 gösterge ile faaliyetler izlenmiştir. Göstergelerden \%70,59'u yani 12 tanesi çok iyi bir şekilde hedeflenen değerlere ulaşılmış olup, 1 tanesi iyi, 2 tanesi orta, 2 tanesi çok zayıf olarak gerçekleşmiştir. Sonuçta bu amacı gerçekleştirmek için göstergelerin 15 tanesi yani \%88,23'i orta ve ortanın üstünde bir değere sahip olup 2 gösterge de \%11,76'lik bir kısımda gerçekleşme değerine ulaşmada zayıf kalmıştır.

- “Önce insan anlayışı doğrultusunda verimli, kaliteli ve etkin bir personel politikası geliştirerek sunulan hizmet kalitesini yükseltmek" Stratejik amacın gerçekleştirilmesi; 2017 yılında toplam 6 gösterge ile faaliyetler izlenmiştir. Göstergelerin \%100'ü yani 6 tanesi çok iyi bir şekilde hedeflenen değerlere ulaşılmıştır. Sonuçta bu amacı gerçekleştirmek için göstergelerin 6 tanesi yani \%100'ü orta ve ortanın üstünde bir değere sahip olarak istenilen başarıyı yakalamıştır.

- “Yenilikçi ve araştırmacı yöntemlerle mali kaynaklarımızı ve varlıklarımızı etkin, verimli ve hesap verebilir bir anlayışla yönetmek" Stratejik amacın gerçekleştirilmesi; 2017 yılında toplam 34 gösterge ile faaliyetler izlenmiştir. Göstergelerin $\% 85,29$ 'sı yani 29 tanesi çok iyi bir şekilde hedeflenen değerlere ulaşmış olup, 1 tanesi iyi, 1 tanesi orta, 3 tanesi çok zayıf olarak gerçekleşmiştir. İlgili amacı gerçekleştirmek için göstergelerin 31 tanesi yani \%91,17'si orta ve ortanın üstünde bir değere sahip olup 3 gösterge yani $\% 8,82$ 'l1k bir kısmı gerçekleşme değerine ulaşmada zayıf kalmiştır.

- “Modern çağın gereklerine uyum sağlayarak kurumun ve ilgili paydaşların bilgi, iletişim ve lojistik hizmetlerden en verimli şekilde yararlanmasını sağlamak" Stratejik amacın gerçekleştirilmesi; 2017 yılında toplam 74 gösterge ile faaliyetler gözlemlenmiştir. Bu göstergelerin 63 tanesi çok iyi bir şekilde hedeflenen değerlere ulaşmış olup, 4 tanesi iyi, 6 tanesi orta, 1 tanesi zayıf olarak gerçekleşmiştir. Sonuçta bu amacı gerçekleştirmek için göstergelerin 73 tanesi orta ve ortanın üstünde bir değere sahip olup 1 gösterge yani \%1,35'lük bir kısmı gerçekleşme değerine ulaşmada zayıf kalmıştır.

- “Etkin denetim mekanizmaları yoluyla kurumsal karar ve süreçlerin hukukun temel ilkeleri çerçevesinde yürütülmesini sağlamak (mevzuat)" Stratejik amacın gerçekleştirilmesi; 2017 yılında toplam 8 gösterge ile faaliyetler gözlemlenmiştir. Bu göstergelerin 7 tanesi çok iyi, 1 tanesi orta olarak hedeflenen değerler yakalanmıştır. Sonuçta 
bu amacı gerçekleştirmek için göstergelerin 8 tanesi yani \%100'ü orta ve ortanın üstünde bir değere sahip olarak gerçekleşmiştir.

- “Vatandaşların memnuniyet düzeyini öncelikli ele alan, güler yüzlü, çağdaş bir yaklaşımla, paydaşlarla iş birliği içerisinde kurumun ve ilçenin görünürlük ve bilinirliğini artırmak" Stratejik amacının gerçekleştirilmesi; 2017 yılında toplam 90 gösterge ile faaliyetler gözlemlenmiştir. Bu göstergelerin 71 tanesi çok iyi bir şekilde hedeflenen değerler yakalanmıştır. 6 tanesi iyi, 5 tanesi orta, 3 tanesi zayıf, 5 tanesi çok zayıf olarak gerçekleşmiştir. İlgili amacı gerçekleştirmek için göstergelerin 82 tanesi yani $\% 91,12$ 'si orta ve ortanın üstünde değerlere ulaşmıştır. \%8,88'lük bir kısmı gerçekleşme değerine ulaşmada zayıf kalmıştır.

Strateji Yönetim Bilgi Sistemi üzerinden, performans gösterge girişleri yapılırken göstergenin türü kısmındaki seçim bölmesi tıklanarak, gösterge türü seçilebilmektedir. Performans göstergeleri için diğer kriterler de göstergenin ölçüm birimi, göstergenin ölçüm sıkl1ğ1, ölçüm şekli ve göstergenin izleme ya da performans göstergesi olup olmadığı ile ilgili girişler yapılarak kaydedilir. Göstergenin ölçüm şekli yedi farklı formül uygulanmaktadır. Bu formüller otomasyon sistemine tanıtılmakta ve ölçümlerin doğru yapılması sağlanmaktadır. Ölçüm şekilleri; Toplanan, sabit, ortalama, ters orantı toplanan, ters orantı sabit, ters orantı ortalama, artan oranlı olmak üzere formüle edilmektedir.

Stratejik plandan gelen orta ve uzun vadeli hedefler ile y1llık performans programindan gelen performans he- deflerini ölçmek için belirlenen performans göstergelerinin gerçekleşmelerinin anlamlılıklarına baktığımızda, 419 göstergenin 329 tanesi yani \%78,5'i anlaml, 36 tanesi yani \%9'u için hedef daha dikkatli ve doğru olarak oluşturulmalı, 10 hedef yani \%2'si gerçekleşmeye göre tutarsız, 44 tanesi yani \%10,5'inde ise gerçekleşme hedefin çok üzerinde olarak tamamlanmıştır. (Tablo 7)

Faaliyet ve projelerin ne oranda yerine getirildiğinin ölçmek için kullanılan performans göstergelerinin yıllık performans hedefine ne oranda etki ettiğini ölçmek için etki oranı kullanılmaktadır. Etki oranı; performans hedeflerine ulaşmak için gerçekleştirilen faaliyet ve projelerin bütçelerini, ilgili performans göstergelerine dağ1tılır. Her bir gösterge için ayrılan tutar tüm faaliyet için ayrılan tutara oranlanarak bir etki oranı çıkarılır. Bu etki oranı da yılsonunda performans programının gerçekleşme oranı ile çarpılarak performans hedefine ne kadar etki ettiği ortaya çıkmış olur.

2015 y1lından önceki performans ölçümlerinde bu şekilde bir ölçüm yapılmamaktaydı ve her bir performans göstergesinin bütçesi farklı olsa da performans hedefine etkisi aynı olmaktaydı. Daha sonra burada ki eksik noktalar tespit edilerek Stratejik Yönetim Bilgi Sistemi üzerine entegre edilmiştir.

\section{PERFORMANS BİLGİ SİSTEMININN DEĞERLENDİRİLMESİ}

Performans programında yer alan performans gösterge gerçekleşmeleri, Strateji Geliştirme Müdürlüğü tarafından performans programı dönemi içinde dört çeyrek halinde birimlerden üçer aylık periyotlar ile toplanarak

Tablo 7. Stratejik Amaçlara Göre Gösterge Hedeflerinin Kontrol Durumu

\begin{tabular}{|c|c|c|c|c|c|c|c|c|c|c|c|c|c|c|c|c|c|c|c|c|c|c|c|c|c|c|c|c|c|c|}
\hline \multicolumn{31}{|c|}{ STRATEJIK AMAÇLARA GÖRE GÖSTERGE HEDEFLERININ KONTROL DURUMU } \\
\hline \multicolumn{3}{|c|}{$\begin{array}{c}\text { Gösterge Hedeflerinin } \\
\text { Anlamlılığı }\end{array}$} & \multicolumn{2}{|c|}{ Toplam } & \multicolumn{2}{|c|}{ SA1 } & \multicolumn{2}{|c|}{ SA2 } & \multicolumn{2}{|c|}{$\mathbf{S A 3}$} & \multicolumn{2}{|c|}{$\mathrm{SA} 4$} & \multicolumn{2}{|c|}{ SA5 } & \multicolumn{2}{|c|}{ SA6 } & \multicolumn{2}{|c|}{ SA7 } & \multicolumn{2}{|c|}{ SA8 } & \multicolumn{2}{|c|}{ SA9 } & \multicolumn{2}{|c|}{ SA10 } & \multicolumn{2}{|c|}{ SA11 } & \multicolumn{2}{|c|}{ SA12 } & \multicolumn{2}{|c|}{ SA13 } \\
\hline $\begin{array}{c}\text { Hedef } \\
\text { Değer } \\
\text { i \% }\end{array}$ & Simge & Açıklama & Adet & $\%$ & Adet & $\%$ & Adet & $\%$ & Adet & $\%$ & Adet & $\%$ & Adet & $\%$ & Adet & $\%$ & Adet & $\%$ & Adet & $\%$ & Adet & $\%$ & Adet & $\%$ & Adet & $\%$ & Adet & $\%$ & Adet & $\%$ \\
\hline$>150$ & 3 & $\begin{array}{l}\text { Gerceklessme } \\
\text { Hedefin Cok } \\
\text { Uzzerinde }\end{array}$ & 44 & 9,89 & 8 & 13,3 & 4 & 20 & 1 & 9,09 & 8 & 14,3 & 8 & 22,9 & 2 & 10,5 & 0 & 0 & 3 & 17,7 & 0 & 0 & 4 & 11,8 & 2 & 2,7 & 0 & 0 & 4 & 4,44 \\
\hline $\begin{array}{l}>70 \\
\text { ve } \\
150\end{array}$ & 2 & $\begin{array}{l}\text { Hedefe Göre } \\
\text { Gerceklesesme } \\
\text { Atrlaml1 }\end{array}$ & 329 & 73,9 & 30 & 50 & 10 & 50 & 7 & 63,6 & 37 & 66,1 & 23 & 65,7 & 16 & 84,2 & 15 & 100 & 11 & 64,7 & 6 & 100 & 26 & 76,5 & 67 & 90,5 & 7 & 87,5 & 74 & 82,2 \\
\hline $\begin{array}{l}>30 \\
\text { ve } \\
70\end{array}$ & & $\begin{array}{l}\text { Yeni Hedef } \\
\text { Daha Dikkatli } \\
\text { Belirlenmeli }\end{array}$ & 36 & 8,09 & 5 & 8,33 & 2 & 10 & 3 & 27,3 & 2 & 3,57 & 4 & 11,4 & 1 & 5,26 & 0 & 0 & 3 & 17,7 & 0 & 0 & 1 & 2,94 & 5 & 6,76 & 1 & 12,5 & 9 & 10 \\
\hline$<30$ & x & $\begin{array}{l}\text { Gerçekleşme } \\
\text { ye Göre } \\
\text { Hedef } \\
\text { Tutarsız }\end{array}$ & 36 & 8,09 & 17 & 28,3 & 4 & 20 & 0 & 0 & 9 & 16,1 & 0 & 0 & 0 & 0 & 0 & 0 & 0 & 0 & 0 & 0 & 3 & 8,82 & 0 & 0 & 0 & 0 & 3 & 3,33 \\
\hline Toplam & & & 445 & $\begin{array}{l}100 \\
\%\end{array}$ & 60 & $\begin{array}{l}100 \\
\%\end{array}$ & 20 & $\begin{array}{l}100 \\
\%\end{array}$ & 11 & $\begin{array}{l}100 \\
\%\end{array}$ & 56 & $\begin{array}{c}100 \\
\%\end{array}$ & 35 & $\begin{array}{l}100 \\
\%\end{array}$ & 19 & $\begin{array}{l}100 \\
\%\end{array}$ & 15 & $\begin{array}{l}100 \\
\%\end{array}$ & 17 & $\begin{array}{l}100 \\
\%\end{array}$ & 6 & $\begin{array}{l}100 \\
\%\end{array}$ & 34 & $\begin{array}{l}100 \\
\%\end{array}$ & 74 & $\begin{array}{l}100 \\
\%\end{array}$ & 8 & $\begin{array}{l}100 \\
\%\end{array}$ & 90 & $\begin{array}{l}100 \\
\%\end{array}$ \\
\hline
\end{tabular}


konsolide edildikten sonra konsolide rapor üst yönetime sunulmaktadır. Performans göstergelerinin hedefe göre yıllık gerçekleşme oranları ve hedeflere ne oranda ulaşıldığı bir otomasyon sistemi aracılığı ile ölçülmektedir ve bunun sonucunda da gerekli değerlendirmeler yapıldıktan sonra başarısızlıkların nedenleri ortaya çıkarılarak gerekli önlemler alınmaktadır.

Strateji Yönetim Bilgi Sistemi üzerinde performans programının izlenmesi sürecinde başarı değerlendirmesi şu kriterlere göre raporlanmaktadır; Stratejik Yönetim Bilgi Sisteminde; hedef ve gerçekleşmenin karşılaştırılması neticesinde;

- \% 85 ve üstü gerçekleşme aralığındaki göstergelerin; çok iyi seviyede kabul edilmesi, yeşil renk ile kodlanması ve 100 puan ile değerlendirilmesi,

- $\quad$ \% 70-84 gerçekleşme aralığındaki göstergelerin; iyi seviyede kabul edilmesi, açık yeşil ile kodlanması ve 75 puan ile değerlendirilmesi,

- 55-69 gerçekleşme aralığındaki göstergelerin orta seviyede kabul edilmesi, mavi renk ile kodlanması ve 50 puan ile değerlendirilmesi,

- $\quad$ \% 45-54 gerçekleşme aralığındaki göstergelerin zayıf seviyede kabul edilmesi, turuncu renk ile kodlanması ve 25 puan ile değerlendirilmesi,

- \% 0-44 gerçekleşme aralığındaki göstergelerin ise çok zayıf seviyede kabul edilmesi, kırmızı renk ile kodlanması ve 0 puan ile değerlendirilmesi şeklindedir.

\section{SONUÇ}

İşletmelerde başarı ile uygulanan Dengeli Sonuç Kartı uygulamasının yerel yönetimlerde uygulanmasına yönelik "Küçükçekmece Belediyesi Dengeli Sonuç Kartı Başarı Karnesi Uygulaması" ilk defa çalışılmıştır. Dengeli Sonuç Kartı boyutları içerisinde yer alan amaçlar neden-sonuç ilişkisi kurularak birbirine bağlanmıştır. Bu boyutların kurum stratejileri ile bağlantılı olması son derece önemli olarak görülmektedir.

Görev kartları ve iş süreçlerinin entegre edilmesi ile, kamuda finansal anlamda gelişmeye açık bir taraf oluşturabileceği, finansal anlamda meydana gelecek iyileşmeler sayesinde kamusal hizmetlerin miktarının ve kalitesinin artabileceği, bu sayede kamusal hizmet alıcılarında memnuniyet düzeyinde artış yaşanacağı düşünülmektedir. İşs süreçlerinin daha derinlik içeren ve halka yakın dokunma anlamında daha ön planda olduğu hizmetlerde iyileştirilmesi önem arz etmektedir. Belediyelerde görevli personellerin iş süreçlerine ait görev kartları, personellerin uzmanlık alanları ile doğrudan orantılı olmalı, görev kartlarında yer alan işlerle ilgili personeller eğitilmeli, öğrenme ve gelişme boyutu sürekli açık tutulmalıdır.
Sonuç olarak; Performansın finansal, müşteri, süreçler ile öğrenme ve gelişme boyutlarının karşılığı; belediyeler tarafından belirlenen stratejik alanlara denk gelmektedir. Yine İstanbul ili Belediyelerinde yapılan çalışma ile performans yönetimi konusunda belediyelerin Dengeli Sonuç Kartı uygulamasını yaptıklarını fakat uyguladıklarının farkında olmadıkları gözlemlenmiştir.

Küçükçekmece belediyesi olarak kurumsal başarı karnesi çalışmaları devam etmektedir, Küçükçe kmece belediyesinin stratejik planlama sürecinin bir yıllık dilimi olan 2017 yılı performans programında yer alan performans hedeflerinin ve hedefleri ölçmek için kullanılan performans göstergelerinin kurumsal performans başarı karnesi çalışmasında yer alan sonuçları şu şekildedir; Başarı puan aralığına göre gerçekleşme değeri \%81 üzerinde olan göstergeler için 100 puan, gerçekleşme değeri \%(61-80) aralığında olan göstergeler için 80 puan, gerçekleşme değeri \%(61-80) aralığında olan göstergeler için 80 puan, gerçekleşme değeri \%(21-40) aralığında olan göstergeler için 40 puan, gerçekleşme değeri \%(0-20) aralığında olan göstergeler için 0 puan verilerek puanlama yapılmaktadır. Amaçların başarıları ölçülürken, amaçlara hizmet eden performans göstergelerinin verilen aralıklara göre puanlamaları yapılarak toplam puanları çıkarılmaktadır. Toplam puan amaca hizmet eden gösterge sayısına bölündüğünde ise amacın ortalama başarısı bulunmaktadır. Tüm stratejik amaçların ortalama başarı puanları hesaplandıktan sonra ise toplam başarı puanları toplanıp ortalaması alındıktan sonra ilgili yılın genel başarı karne puanına ulaşılmaktadır.

“ Küçükçekmece Belediyesi 2017 Y1lı Performans Sonuçlarına Göre Yapılan Kurumsal Başarı Karnesi Çalışmasında;" toplamda 13 amacın her biri için hesaplanan puanların ortalaması alındığında \% 91 oranında bir başarının yakalandığı sonucuna ulaşılmıştır.

\section{KAYNAKÇA}

EFE, Ş. (2012). Kamuda Stratejik Planlamaya Dayalı Performans Yönetimi: Türkiye Uygulaması ve Sorunları. Sayıştay Dergisi, 121.

HORNGEN, C., DATAR, S., \& FOSTER, G. (2003). Cost Accounting: A Managerial Emphasis. Prentice Hall, 450.

JOHNSON, H. T., \& KAPLAn, R. S. (1991). Relevance Lost: The Rise and Fall of Management Accounting. Harvard Business Scholl Press, 253-263. 
KAPLAN, R. S., \& NORTON, D. P. (1992). The Balanced Scorecard-Measures that Dive Performance. Harvard BusinessReview, 72.

KAPLAN, R., \& NORTON, D. (1996). Translating Strategy Into Action: The Balanced Scorecard. Harvard Business School Press, 9.

NIVEN, P. R. (2003). Balanced scorecard step-by-step for government and not-for-profit agencies. New Jersey: John Wiley \& Sons.

RAYNUS, J. (2019). Improving Business Process Performance: Gain Agility, Create Value, and Achieve Success (s. 62-65). New York: CRC Press.

YILMAZ, V. (2019, Ocak). Türkiye'de Yerel Yönetimlerde Performans Yönetimi İstanbul Büyükşehir Belediyesi Örneği. Yalova, Türkiye.

https://kucukcekmece.istanbul/Content/dosya/7837/ performans-programi-2017-54391-2632485.pdf 